\title{
Climate Change Projection in the Twenty-First Century Simulated by NIMS-KMA CMIP6 Model Based on New GHGs Concentration Pathways
}

\author{
Hyun Min Sung ${ }^{1}$ (D) Jisun Kim ${ }^{1}$. Sungbo Shim ${ }^{1} \cdot$ Jeong-byn Seo ${ }^{1}$ Sang-Hoon Kwon ${ }^{1} \cdot$ Min-Ah Sun ${ }^{1} \cdot$ Hyejin Moon ${ }^{1}$. \\ Jae-Hee Lee ${ }^{1} \cdot$ Yoon-Jin Lim ${ }^{2} \cdot$ Kyung-On Boo ${ }^{3} \cdot$ Youngmi Kim $^{4}$ • Johan Lee ${ }^{3}$. Jiwoo Lee ${ }^{5}$ Jun-su Kim ${ }^{2}$. \\ Charline Marzin ${ }^{6} \cdot$ Young-Hwa Byun ${ }^{1}$
}

Received: 17 April 2020 / Revised: 29 October 2020 / Accepted: 5 January 2021 / Published online: 20 January 2021

(C) The Author(s) 2021

\begin{abstract}
The National Institute of Meteorological Sciences-Korea Meteorological Administration (NIMS-KMA) has participated in the Coupled Model Inter-comparison Project (CMIP) and provided long-term simulations using the coupled climate model. The NIMS-KMA produces new future projections using the ensemble mean of KMA Advanced Community Earth system model (KACE) and UK Earth System Model version1 (UKESM1) simulations to provide scientific information of future climate changes. In this study, we analyze four experiments those conducted following the new shared socioeconomic pathway (SSP) based scenarios to examine projected climate change in the twenty-first century. Present day (PD) simulations show high performance skill in both climate mean and variability, which provide a reliability of the climate models and reduces the uncertainty in response to future forcing. In future projections, global temperature increases from $1.92{ }^{\circ} \mathrm{C}$ to $5.20{ }^{\circ} \mathrm{C}$ relative to the $\mathrm{PD}$ level (1995-2014). Global mean precipitation increases from $5.1 \%$ to $10.1 \%$ and sea ice extent decreases from $19 \%$ to $62 \%$ in the Arctic and from $18 \%$ to $54 \%$ in the Antarctic. In addition, climate changes are accelerating toward the late twenty-first century. Our CMIP6 simulations are released to the public through the Earth System Grid Federation (ESGF) international data sharing portal and are used to support the establishment of the national adaptation plan for climate change in South Korea.
\end{abstract}

Keywords CMIP6 $\cdot$ ScenarioMIP $\cdot$ SSP-RCP $\cdot$ Climate change $\cdot$ Future projection

Responsible Editor: Eun-Soon Im.

Hyun Min Sung

sunghm122@korea.kr

1 Innovative Meteorological Research Department, Climate Research Division, National Institute of Meteorological Sciences, Seogwipo, Jeju, South Korea

2 Numerical Model Development Division, Numerical Modelling Center, Seoul, South Korea

3 Operational Systems Development Department, National Institute of Meteorological Sciences, Seogwipo, Jeju, South Korea

4 Planning and Finance Division, National Institute of Meteorological Sciences, Seogwipo, Jeju, South Korea

5 Program for Climate Model Diagnosis and Intercomparison, Lawrence Livermore National Laboratory, Livermore, CA, USA

6 Met Office Hadley Centre, Exeter, UK

\section{Introduction}

For the Intergovernmental Panel on Climate Change (IPCC) Assessment Report 6 (AR6), a new phase of model experimentation (CMIP6) is on progress. Projection of the future climate change plays an important role in improving understanding of the climate system (O’Neill et al. 2016). The Scenario Model Inter-comparison Project (ScenarioMIP) is an essential protocol within CMIP6 that provide multi-model climate projections based on new future simulations (Eyring et al. 2016). The highest priority objective for the ScenarioMIP is to provide climate model simulations that can facilitate a wide range of integrated studies for climate impact on societies, including the considerations of mitigation and adaptation.

The NIMS-KMA has participated in the ScenarioMIP since CMIP3. Min et al. (2006) produce the ECHO-G model simulations under the Special Report on Emission Scenarios (SRES) of the CMIP3. Also, NIMS-KMA provides the Hadley Global Environment Model (HadGEM2-AO; Collins 
et al. 2011) simulations under Representative Concentration Pathway scenarios (RCPs; Moss et al. 2010). After CMIP5, a new concept for scenario has been developed by combination of RCPs and SSPs. In this new concentration pathway, future climate response depends on the choices and implementation of adaptation and mitigation options. The updated projections of the climate state are required in CMIP6 based on the new $\mathrm{CO}_{2}$ concentration pathways. Four Tier 1 scenarios (SSP1-2.6, SSP2-4.5, SSP3-7.0, and SSP5-8.5) are selected for our simulations.

For contributing to CMIP6, we use two Earth system models (i.e., K-ACE and UKESM1) under the Met Office collaboration agreement. Lee et al. (2019a) and Sellar et al. (2019) report evaluation results for K-ACE and UKESM1, respectively, while there has been no study about the ensemble mean evaluation. In this study, we aim to show performance of the ensemble mean and their future climate changes in the twenty-first century. Climate change indicators, such as temperature, precipitation, sea-ice, and climate extreme indices are analyzed for future projections. We also focus on near-term (NT; 2021-2040), mid-term (MT; 2041-2060), and long-term (LT; 2081-2100) period to provide information of future climate change.

This study is organized as follows. The next section describes the framework of CMIP6 experiments. The general performance of CMIP6 experiments is analyzed in section 3 . Section 4 describes the climate change projections for the twenty-first century using the new SSP-RCP scenarios focusing on temperature, precipitation, sea-ice, and climate extreme indices. Finally, section 5 presents the discussion and conclusion.

\section{Model Description and Experiments}

\subsection{Model Description}

The K-ACE has been developed by the NIMS-KMA under the South Korea-United Kingdom (UK) Science and Technology Cooperation Program (Lee et al. 2019a). The compositions of K-ACE are the Unified Model (UM) in the Global Atmosphere 7.1 configuration (GA7.1; Walters et al. 2019), Modular Ocean Model of GFDL (MOM; Griffies et al. 2007), sea ice model of Los Alamos (CICE; Hunke et al. 2015; Ridley et al. 2018), and the OASIS3-MCT coupler (Craig et al. 2017; Valcke et al. 2015). The horizontal resolution is a N96 regular latitude-longitude grid in atmosphere. Land surface component is the joint UK land environment simulator (JULES; Best et al. 2011).

The UKESM1 has been developed by the UK Met Office (UKMO) and the Natural Environment Research Council (NERC). The ocean and aerosol-chemistry processes are the key differences between K-ACE and UKESM1. The ocean component of UKESM1 and K-ACE is the Nucleus for European Modelling of the Ocean dynamical model (NEMO) and MOM, respectively. This component is coupled through the OASIS3-MCT coupler. In addition, an aerosol component of $\mathrm{K}-\mathrm{ACE}$ is the simple mode of the United Kingdom Chemistry and Aerosol model (UKCA; Archibald et al. 2019, Mulcahy et al. 2018), while a fully coupled UKCA is used in UKESM1. The detailed description of the model components and the coupling process of two Earth system models are described in Lee et al. (2019a) and Sellar et al. (2019). These simulation results (both K-ACE and UKESM1) are released to the international data sharing portal (ESGF) and are used to support the establishment of the national adaptation plan for climate change in South Korea.

We simulate three ensemble members for each of the KACE (r1i1p1f1, r2ilp1f1, and r3ilp1f1) and the UKESM1 (r13i1p1f2, r14i1p1f2, and r15i1p1f2). The ensemble mean isused for analysis, which is described as NIMS-KMACMIP6. Also, it is worth to document their comparison with NIMS-KMA's CMIP5 model (HadGEM2-AO; Baek et al. 2013). The HadGEM2-AO comprises atmosphere component with N96 horizontal resolution and ocean component with a 1 degree horizontal resolution (increasing to $1 / 3$ degree at the equator). The atmospheric component is the previous version of UM.

\subsection{Experimental Design and External Forcing}

Historical experiments (1850-2014) and future projection experiments $(2015 \sim 2100)$ have been performed with the $\mathrm{K}$ ACE and the UKESM1. In CMIP6, similar to the earlier phases of CMIP, the pre-industrial control simulation is used to produce a stable quasi-equilibrium for initial state for the historical experiment (O’Neill et al. 2016). Following that, historical experiments are performed using external conditions (e.g., GHGs, aerosols, land use changes, and natural forcing). We select five gases $\left(\mathrm{CO}_{2}, \mathrm{CH}_{4}, \mathrm{~N}_{2} \mathrm{O}\right.$ (WMO 2014), CFC-12-eq (Velders et al. 2009), HFC-134a-eq) to represent anthropogenic radiative forcing (Meinshausen et al. 2017). Aerosol emission sources have been obtained from Input4MIPs (Durack et al. 2018) and are associated with biofuel, fossil fuel, and biomass burning emissions (Bond et al., 2004). The ending states of the historical experiments are applied as initial condition for future projection experiments. Future projection experiments are performed using Tier 1 scenarios (SSP1-2.6, SSP2-4.5, SSP3-7.0, and SSP5-8.5). According to Gidden et al. (2019), in SSP1, rapid world energy transition from fossil-fuel related energy consumption sharply decreases the emissions and SSP2 has a similar transition with delayed action. Only SSP3 shows similar emissions to present-day levels due to the increasing demand of growing population. 


\section{Evaluation of Historical Experiments}

\subsection{General Performance of the Mean State}

Evaluation of the historical simulation provides insights into the reliability of the climate model and reduces the uncertainty in response to future forcing (Eyring et al. 2016). The purpose of this section is to ensure that the two model ensembles with similar structures use for supporting national policy of climate change adaptation, but the calculated results also have comparable from a scientific point of view. Reichler and Kim (2008) suggest a performance index with aggregated errors to simulate climatological mean states of multiple different climate variables. To apply this method, normalized errors of 20 key climate quantities (Table 1) are used. To determine performance index, we first calculate normalized error variance $\mathrm{e}^{2}$ for each model by normalizing the differences between simulated and observed climates based on grid point. The equation is given below:

$e_{v m}^{2}=\sum_{n}\left(w_{n} \frac{\left(\bar{S}_{v m n}-\bar{O}_{v n}\right)^{2}}{\sigma_{v n}^{2}}\right)$

Where, $\bar{S}_{v m n}$ indicates the simulated climatology for climate variable (v), model $(\mathrm{m})$, and grid point $(n) . \bar{O}_{v n}$ is the corresponding observed climatology. $w_{n}$ is proper weights needed for area and mass average and $\sigma_{v n}^{2}$ is the interannual variance from the validation observations. This approach helps to homogenize errors from different regions and variables. Following that, the final model performance index is calculated by averaging over all variables. The outcomes of the comparison between K-ACE, UKESM1 and 22 CMIP5 models are shown in Fig. 1. As the blue color becomes darker, the error decreases. Note that the CMIP5 historical data are not available after 2005 as the historical simulation ends in this year. Thus, the RCP 4.5 scenario is used for the period from 2006 to 2014. Different scenarios show similar magnitude of climate change in near future (IPCC 2014) and most previous studies use RCP 4.5 scenario for near future period. The NIMS-KMA-CMIP6 (Fig. 1) shows an improved performance in PD period (1995-2014) from historical simulation compared to CMIP5. In addition, K-ACE and UKESM1 show similar performance levels for present climate (Fig. 1b, 1c). This result indicates reduction of the uncertainty in response to future forcing in CMIP6 simulations.

\subsection{Climate Variability}

It is important to examine the simulated performance of climate variability for decadal time scale because the simulation for climate projection is most likely to have hundreds time scale integration. We investigate the performance on
Table 1 Climate variables and corresponding validation data. Those listed as "land" or "ocean" are single-level fields over their respective regions

\begin{tabular}{llll}
\hline Variable & Domain & Acronym & Validation data \\
\hline 2 m air temperature & global & TAS & CRU, ICOADS, NOAA, ERA-Interim \\
Total cloudiness & global & CLT & CERES \\
Surface downwelling shortwave flux in air & global & RSDS & CERES \\
Surface upwelling shortwave flux in air & global & RSUS & CERES \\
Surface downwelling longwave flux in air & global & RLDS & CERES \\
Surface upwelling longwave flux in air & global & RLUS & CERES \\
TOA outgoing shortwave flux & global & RSUT & CERES \\
TOA outgoing longwave flux & global & RLUT & CERES \\
TOA cloud radiative forcing longwave flux & global & CRFLT & CERES \\
TOA cloud radiative forcing shortwave flux & global & CRFST & CERES \\
Precipitation & global & PR & CMAP, GPCP \\
Sea level pressure & ocean & PSL & ICOADS \\
Surface upward sensible heat flux & ocean & HFSS & ICOADS, OAFLUX \\
Surface upward latent heat flux & ocean & HFLS & ICOADS, OAFLUX \\
Surface skin temperature & land & TS & ERA-Interim \\
$200 \mathrm{hPa}$ zonal wind & global & U200 & ERA-Interim \\
$200 \mathrm{hPa}$ meridional wind & global & V200 & ERA-Interim \\
$200 \mathrm{hPa}$ air temperature & global & T200 & ERA-Interim \\
$850 \mathrm{hPa}$ zonal wind & global & U850 & ERA-Interim \\
$850 \mathrm{hPa}$ meridional wind & global & V850 & ERA-Interim \\
\hline & & & \\
\hline
\end{tabular}


(a) NIMS-CMIP6

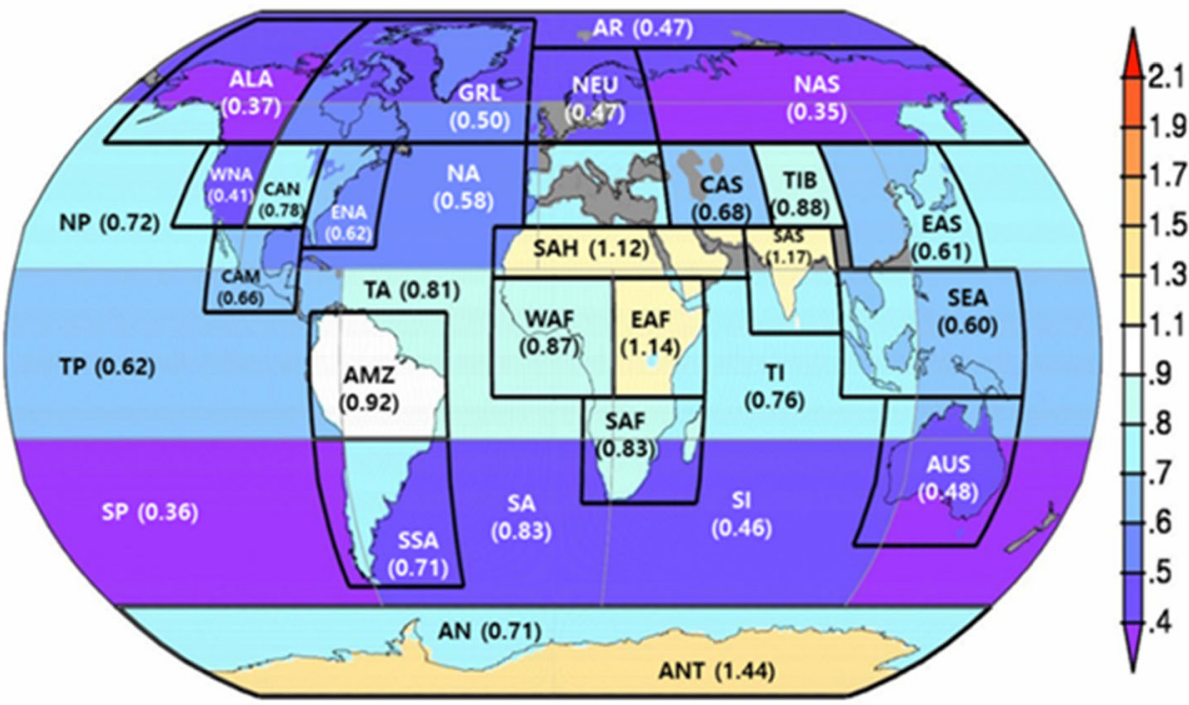

(b) K-ACE

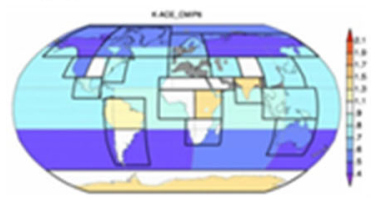

(f) HadGEM2-CC

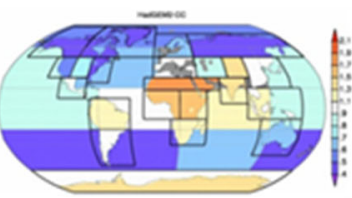

(j) CanCM4

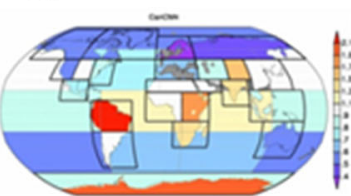

(n) CanESM2

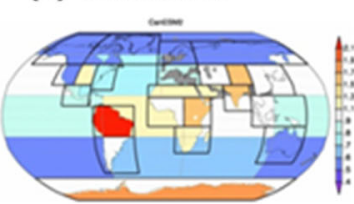

(r) CCSM4

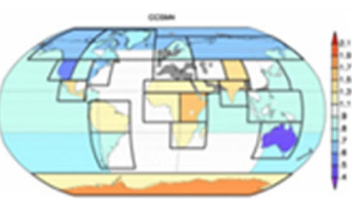

(v) CESM1-CAM5-1-FV2

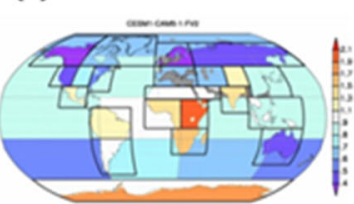

(c) UKESM1

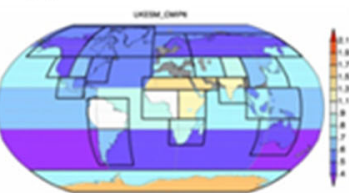

(g) HadGEM2-ES

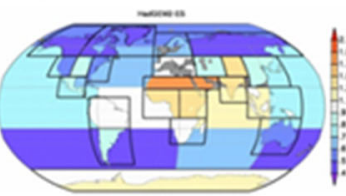

(k) GFDL-CM3

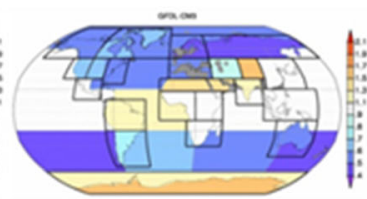

(o) GFDL-ESM2G

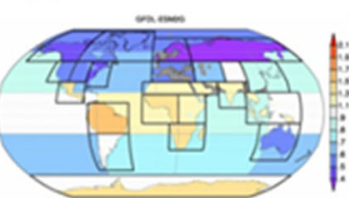

(s) GFDL-ESM2M

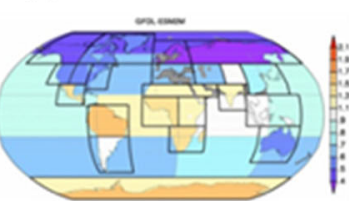

(W) MIROC-ESM-CHEM

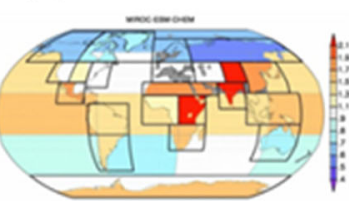

(d) HadGEM2-AO

(e) ACCESS1-0

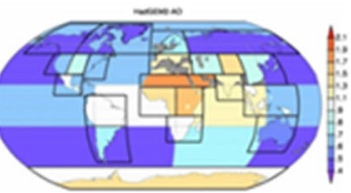

(h) BCC-CSM1-1

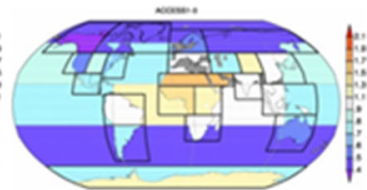

(i) IPSL-CM5A-LR
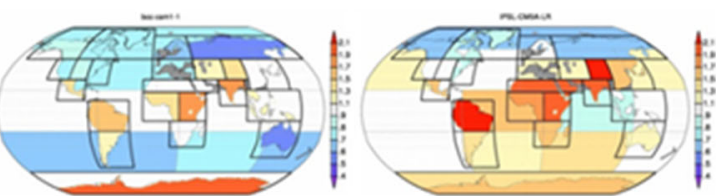

(I) CNRM-CM5

(m) IPSL-CM5A-MR

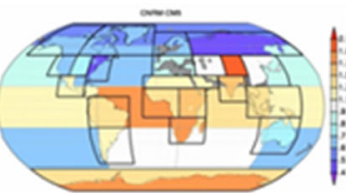

(p) MIROC4h

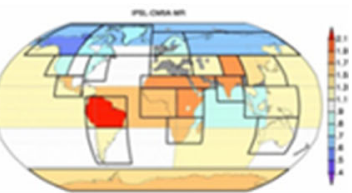

(q) MPI-ESM-LR
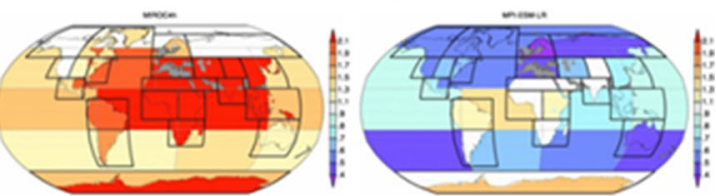

(t) MIROC5

(u) MRI-CGCM3
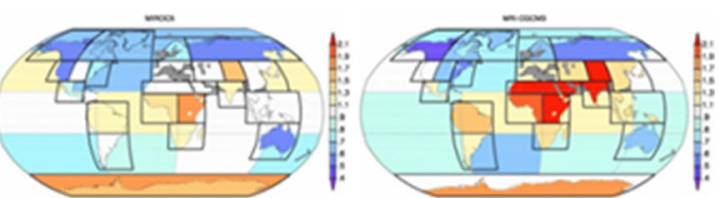

(x) MIROC-ESM

(y) NorESM1-M

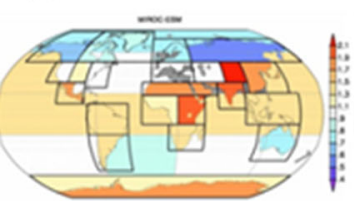


Fig. 1 The calculated performance index over global for (a) NIMS-KMA-CMIP6 results, (b) K-ACE, (c) UKESM1 and (d)(y) 22 CMIP5 models. Low indices (blue color) denote better performance

reproducing various climate variability modes using the Program for Climate Model Diagnosis and Inter-comparison (PCMDI) Metrics Package (PMP; Gleckler et al. 2016, Lee et al. 2019b). The atmospheric modes (Northern Annular Mode (NAM), the North Atlantic Oscillation (NAO), the Pacific North America pattern (PNA), the North Pacific Oscillation (NPO), and the Southern Annular Mode (SAM)) and SST based modes (Pacific Decadal Oscillation (PDO) and the North Pacific Gyre Oscillation (NPGO)) are examined in this section. The winter season for the atmospheric modes are the primary focus (i.e., DJF, except for SAM where JJA used), because the variability signal is strongest in winter. The SSTbased modes are derived using monthly-mean time series. The Common Basis Function (CBF) approach (Lee et al. 2019b) is used for evaluation of variability in this study. The twentieth Century Reanalysis (20CR; Compo et al. 2006, 2011) and Met Office Hadley Centre Sea Ice and Sea Surface Temperature dataset (HadISST) version 1.1 (Rayner et al. 2003) are used for atmospheric and SST-based modes, respectively. The observations and models are both analyzed over the period 1900-2005 (1956-2005 for observed SAM due to lower confidence in observations over the Southern Hemisphere in the first half of the twentieth century).

The simulated patterns of each climate variability mode (Fig. 2) indicate that the models reasonably capture the extra-tropical modes. For NAM, PNA, and NPO, K-ACE and UKESM1 show larger variance over the Pacific Ocean, but the locations of dipoles are comparable to the observation. For NAO, models capture smaller variance over the Atlantic Ocean, but locations of dipoles are also comparable to the 20CR as well. It is similar for SAM and PDO where models are performing well at capturing the pattern. For NPGO, however, there are discrepancies between HadISSTv1.1 (Fig. 2y) and models (Fig. 2z-ab), which are more noticeable than other modes. Overall, models are promising to capture patterns and amplitudes of modes in general except for the NPGO (amplitude not shown). With the analysis from previous session, these results demonstrate the high reliability of future projections for the twenty-first century.

\section{Future Climate Projections}

In section 3, we investigated the performance of K-ACE and UKESM1 for the PD period compared to observations. Two climate models show similar performances for climate mean state and variability. Therefore, we analyzed ensemble mean for future climate change over the twenty-first century. In addition, this section provides information on how much change isprojected by the future projections for the new climate change scenario through comparing the NIMS-KMA's CMIP5 results (Baek et al. 2013). This information supports the establishment of national adaptation policies for climate change and can contribute to the spread of the climate emergency.

\subsection{Surface Temperature}

Figure 3 shows the time series of global mean surface temperature changes for the twenty-first century relative to the PD period. The simulated temperature projections have similar positive trends until 2030. As mentioned in AR5, near-term projections are dependent on internal variability rather than the emission scenario. Impact of the emission scenario on future projections becomes evident after the 2030s. In the late twenty-first century, rising temperature and ensemble spreads are proportional to the concentration pathway of four scenarios. On average, the projected range of temperature changes in the $\mathrm{LT}$ period relative to the PD period is expected to be $1.92 \pm 0.22^{\circ} \mathrm{C}, 3.02 \pm 0.47^{\circ} \mathrm{C}$, $4.28 \pm 0.62{ }^{\circ} \mathrm{C}$, and $5.20 \pm 0.71{ }^{\circ} \mathrm{C}$ for SSP1-2.6, SSP2-4.5, SSP3-7.0, and SSP5.8.5, respectively. In addition, the difference in the temperature between SSP5-8.5 and SSP1-2.6 scenarios is about $3.3^{\circ} \mathrm{C}$ by the end of the century, which is larger than the temperature difference between RCP 2.6 and RCP $8.5\left(3{ }^{\circ} \mathrm{C}\right)$ reported in Baek et al. (2013). According to O'Neill et al. (2016), $\mathrm{CO}_{2}$ concentrations in SSP5-8.5 of CMIP6 are higher than RCP8.5 of CMIP5. This means that expected global warming is higher in the new scenario of CMIP6. In addition, CMIP6 models, such as K-ACE and UKESM1, have higher climate sensitivity (ECS; Equilibrium Climate Sensitivity) than CMIP5 models (Zelinka et al. 2020, Sun et al. 2020). The projected future changes are described in Table 2. Consistent with the previous results (Baek et al. 2013), the temperature increase in East Asia is also larger for all scenarios.

Figure 4 illustrates the spatial pattern of global surface temperature in the twenty-first century under four future scenarios. The temperature projections are estimated for three periods, NT (2021-2040), MT (2041-2060), and LT (20812100). Continuous increases in temperature are expected in NT, MT, and LT under all scenarios. NT projections are similar in all scenarios. However, LT projections show significant discrepancies in different scenarios compared to NT and MT periods. A larger scale warming in the late twenty-first century over land rather than ocean (right column in Fig. 4) is projected under SSP3-7.0 and SSP5-8.5 (high concentration scenarios). The highest temperature increase is expected to occur in the Arctic regions, with less warming over the North Atlantic and the Southern Ocean. These spatial changes are accelerated due to sea ice melting which is based on increasing temperature (positive surface albedo feedback; IPCC, 2014). 


\section{OBS}

(a)

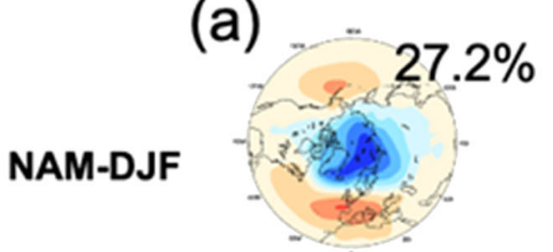

(e)

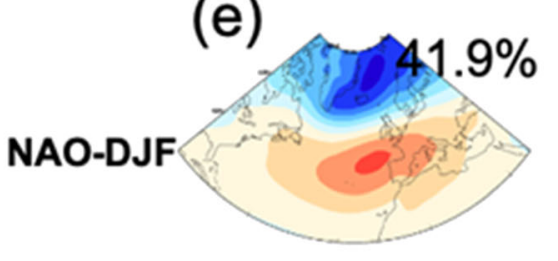

HadGEM2-AO

(b)

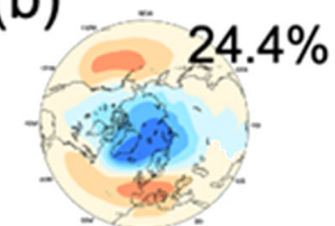

(f)

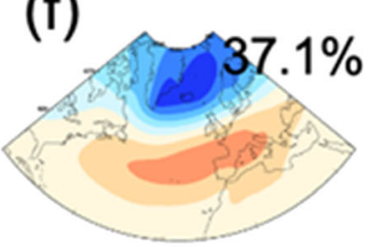

(j)

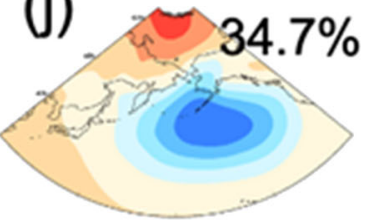

(n)

(m) $23.1 \%$

NPO-DJF

SAM-JJA

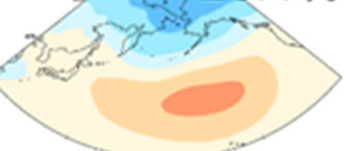

(r) $-30.9 \%$ (c)

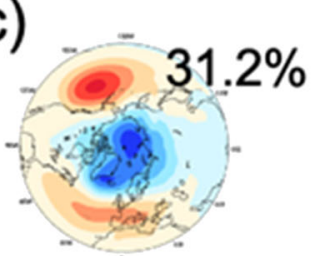

(g)

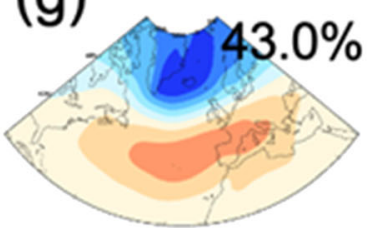

(k) $45.9 \%$

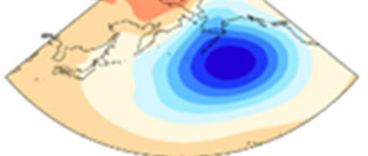

(o) $26.6 \%$

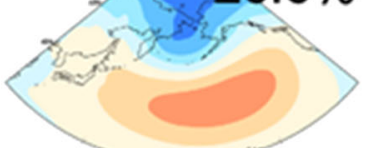

(s)

$35.2 \%$

\section{UKESM}

(d)

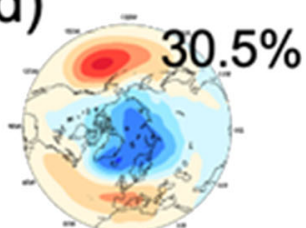

(h)

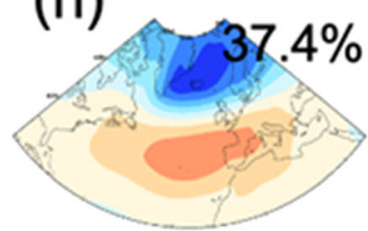

(I) $40.5 \%$

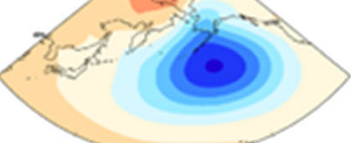

(p)

(t) $\quad 33.6 \%$

PDO-mo
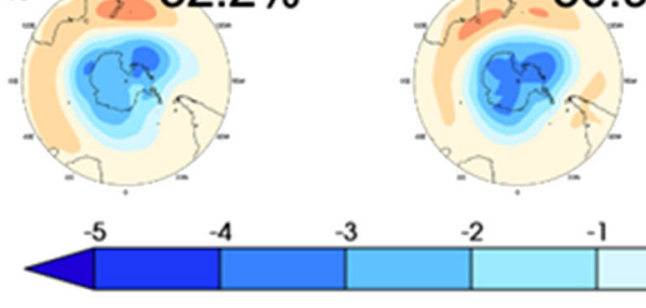

\begin{tabular}{|l|l|l|l|}
3 & -2 & -1 & 0 \\
\hline & & & \\
\hline
\end{tabular}

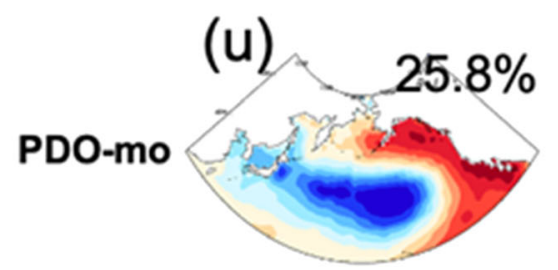

(v)

(w)

(x) $24.0 \%$

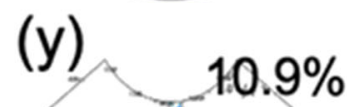

(z)

(aa)

(ab) $10.7 \%$

NPGOmo
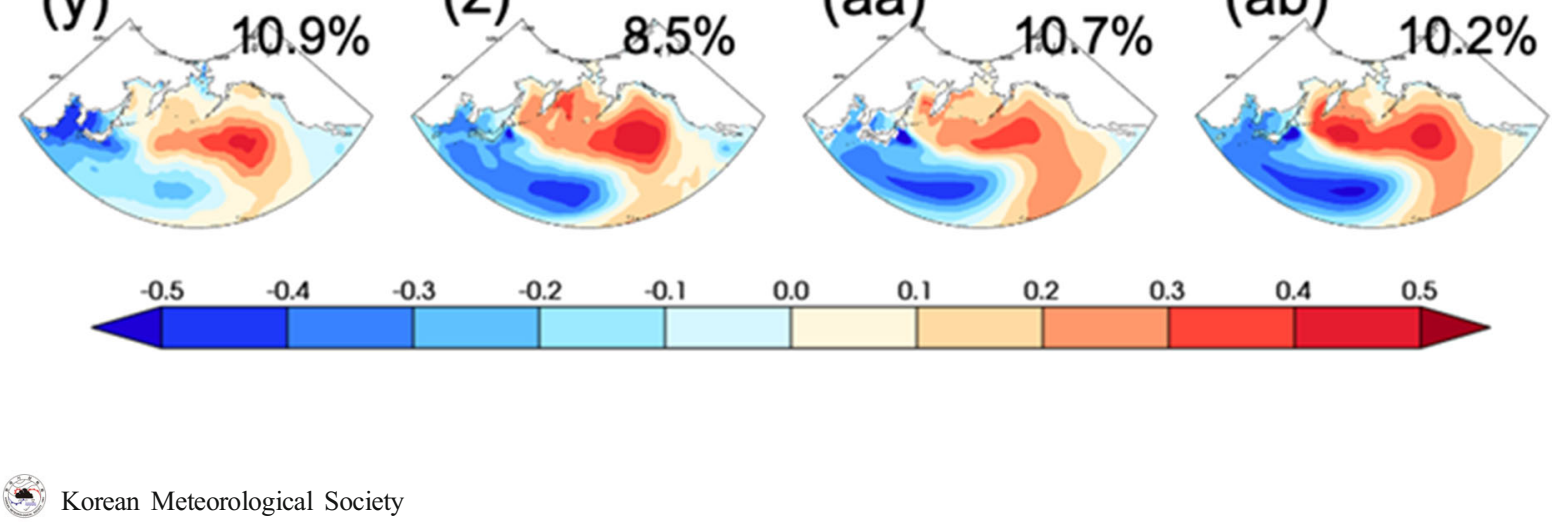
Fig. 2 The observed (EOF-1 or 2; first column) and simulated (CBF) modes of variability from HadGEM2-AO (second column), K-ACE (third column), and UKESM1 (fourth column), respectively. The percent of variance [\%] explained by each $\mathrm{EOF}$ or $\mathrm{CBF}$ is noted at the upper-right corner of each plot. Units for atmospheric and SST-based modes are $\mathrm{hPa}$ and ${ }^{\circ} \mathrm{C}$, respectively

\subsection{Precipitation}

The twenty-first century projection of precipitation also shows larger response in this study than the result reported by Baek et al. (2013). Projected global mean precipitation changes (Fig. 5) demonstrate that all scenarios show significant increases in precipitation with similar trends projected until 2050. Precipitation changes in the LT period relative to the PD period are expected to increase from $5.1 \%$ to $10.1 \%$. Further, SSP1-2.6 and SSP5-8.5 show $5 \%$ precipitation difference in the LT period, and this precipitation differenc'e in 2100 is twice that in CMIP5 (2.5\% in Baek et al. 2013). Additionally, changes in global precipitation with temperature are within the range of $1-3 \%{ }^{\circ} \mathrm{C}^{-1}$ in most climate models (IPCC 2014), and NIMS-KMA-CMIP6 shows comparable precipitation sensitivity $\left(2.7 \%{ }^{\circ} \mathrm{C}^{-1}, 1.9 \%{ }^{\circ} \mathrm{C}^{-1}\right.$ for SSP1-2.6 and SSP5-8.5, respectively).

Spatial patterns of future precipitation changes (\%) in NT projections are similar in all scenarios and the impact of different emission scenarios begins to appear in LT period (Fig. 6). All scenarios reveal the same spatial pattern (increase in tropics and decrease in subtropics) of precipitation changes with different magnitudes. Moreover, the East Asia monsoon and Indian monsoon regions tend to be wetter while the South Asia monsoon and South America monsoon regions become drier. The magnitudes of these patterns are significant in higher concentration scenarios (SSP3-7.0, SSP5-8.5). Overall, East Asian changes are larger than the global climate changes for all scenarios (Table 2).

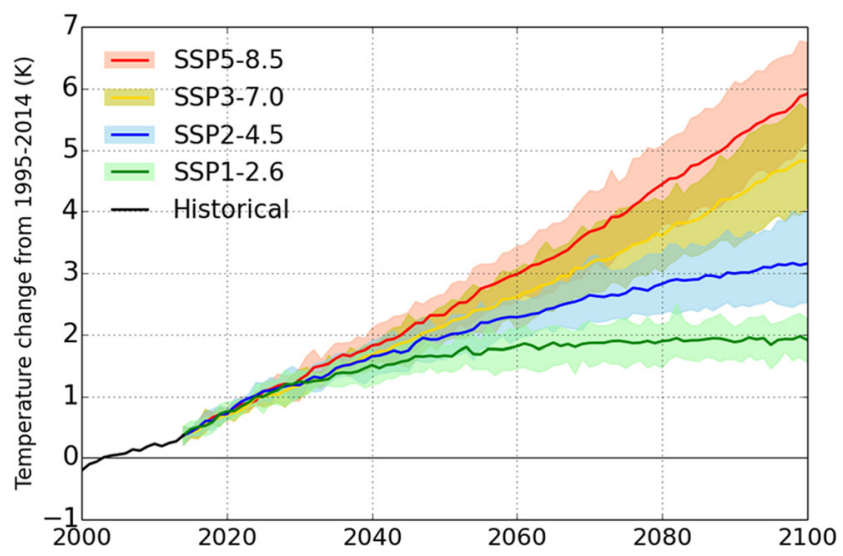

Fig. 3 Time series of global mean surface temperature changes for the historical simulation (black) from 1995 to 2014, and future simulations for four SSP-RCPs (SSP5-8.5 (red), SSP3-7.0 (yellow), SSP2-4.5 (blue), and SSP1-2.6 (green)) from 2015 to 2100 , respectively. The shaded area indicates the ensemble spread of six members (both K-ACE and UKESM1)
Table 2 Projected global mean surface temperature change (tas) and precipitation change in each future period, NT (2021-2040), MT (20412060), and LT (2081-2100) relative to PD period

\begin{tabular}{lllll}
\hline Global & & Near-Term & Mid-Term & Long-Term \\
Tas $\left({ }^{\circ} \mathrm{C}\right)$ & SSP1-2.6 & 1.19 & 1.67 & 1.92 \\
& SSP2-4.5 & 1.25 & 1.99 & 3.02 \\
& SSP3-7.0 & 1.22 & 2.18 & 4.28 \\
& SSP5-8.5 & 1.33 & 2.42 & 5.20 \\
precip. (\%) & SSP1-2.6 & 2.82 & 4.11 & 5.10 \\
& SSP2-4.5 & 2.52 & 4.23 & 6.85 \\
& SSP3-7.0 & 2.09 & 3.84 & 7.88 \\
& SSP5-8.5 & 2.58 & 4.66 & 10.08 \\
East-Asia & & Near-Term & Mid-Term & Long-Term \\
Tas $\left({ }^{\circ}\right.$ C) & SSP1-2.6 & 1.19 & 1.69 & 1.97 \\
& SSP2-4.5 & 1.27 & 2.03 & 2.99 \\
& SSP3-7.0 & 1.24 & 2.18 & 4.33 \\
& SSP5-8.5 & 1.39 & 2.45 & 5.29 \\
precip. $(\%)$ & SSP1-2.6 & 3.39 & 5.30 & 6.31 \\
& SSP2-4.5 & 3.49 & 4.63 & 6.67 \\
& SSP3-7.0 & 3.03 & 5.08 & 7.97 \\
& SSP5-8.5 & 3.68 & 5.16 & 10.21 \\
\hline
\end{tabular}

\subsection{Sea Ice}

Figure 7 shows the time series of the sea ice changes. Similar to temperature changes, the reduction of the sea ice extent until around 2030 is consistent in all four scenarios and the melting trend differs significantly among the scenarios after 2030. The projected sea ice extent in SSP1-2.6 stabilizes after the MT period and the reduction continues in SSP2-4.5. The acceleration of melting occurs after the MT period in SSP3-7.0 and SSP58.5. This is especially evident in the Arctic region, where acceleration is significant and is influenced by the positive ice albedo feedback (increased air temperature reduces sea ice cover, allowing more energy to be absorbed on the sea surface, accelerating the melting; Gregory et al. 2002; Cvijanovic and Ken 2015). In LT period, the sea ice extent decreases from $19 \%$ (SSP1-2.6) to 62\% (SSP5-8.5) in the Arctic and from $18 \%$ (SSP1-2.6) to 54\% (SSP5-8.5) in the Antarctic. The rapid sea ice melting rates in SSP3-7.0 and SSP5-8.5 are associated with high $\mathrm{CO}_{2}$ concentrations (> $\left.600 \mathrm{ppm}\right)$ and temperatures (above $4{ }^{\circ} \mathrm{C}$ ) relative to the pre-industrial levels. Additionally, according to the IPCC AR5, sea ice reduction of the Arctic has been most rapid in summer. A nearly ice-free Arctic (sea ice extent less than $10^{6} \mathrm{~km}^{2}$ for at least five consecutive years) in September is likely after the NT period in all scenarios (not shown). The rate of decline in the Arctic is faster in this study than reported by Baek et al. (2013). However, the Antarctic sea ice loss is projected to continue through the NT period depending on the magnitude of global warming (from $35 \%$ for SSP1-2.6 to 93\% for SSP5-8.5). 

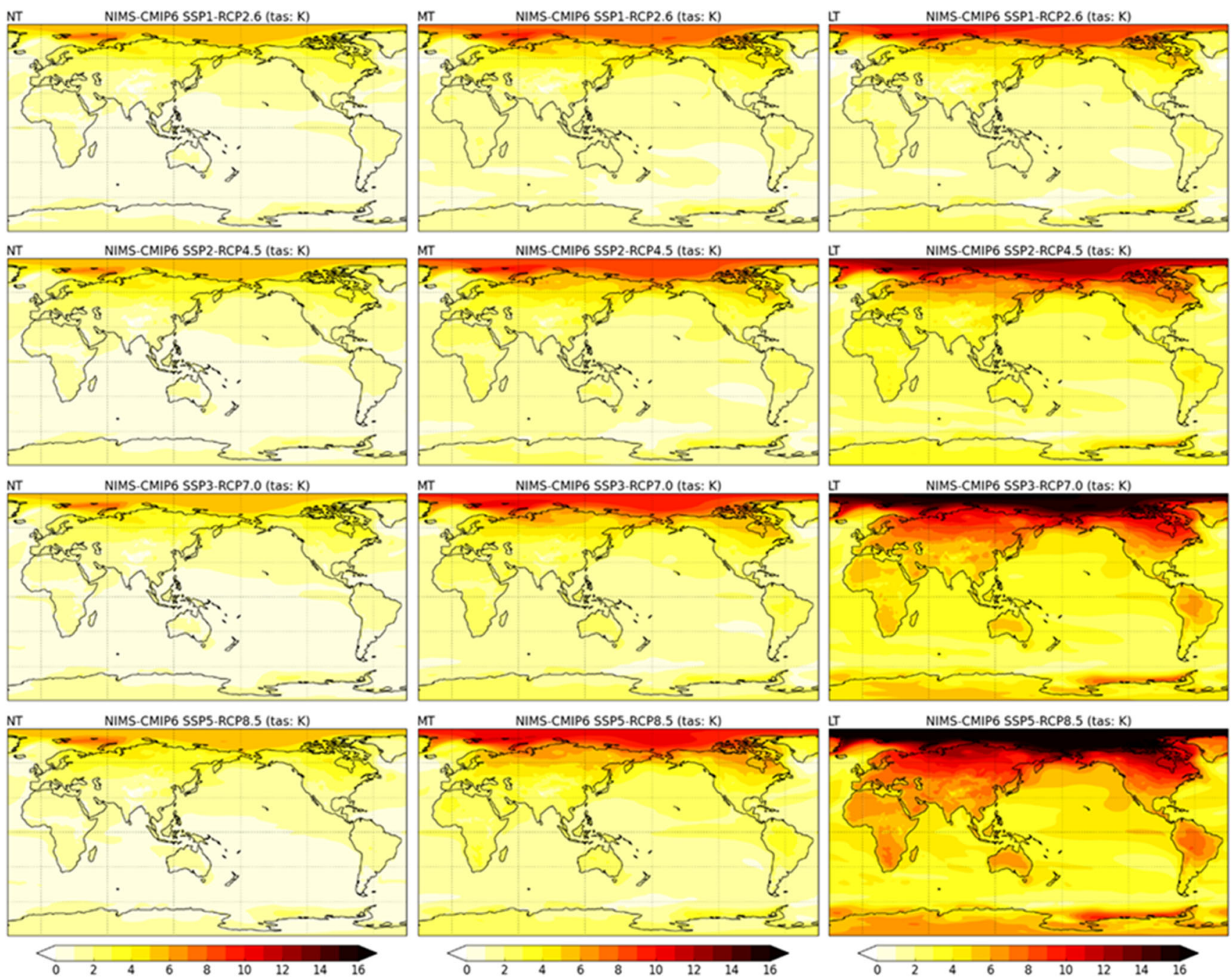

Fig. 4 Global distribution of the 20 year averaged temperature change in twenty-first century of four SSP-RCP future scenarios (SSP1-2.6 (first row), SSP2-4.5 (second row), SSP3-7.0 (third row), and SSP5-8.5

(fourth row)) with three future periods (Near-Term (NT; left column), Mid-Term (MT; mid column), and Long-Term (LT; right column)) compared to PD period (1995-2014)

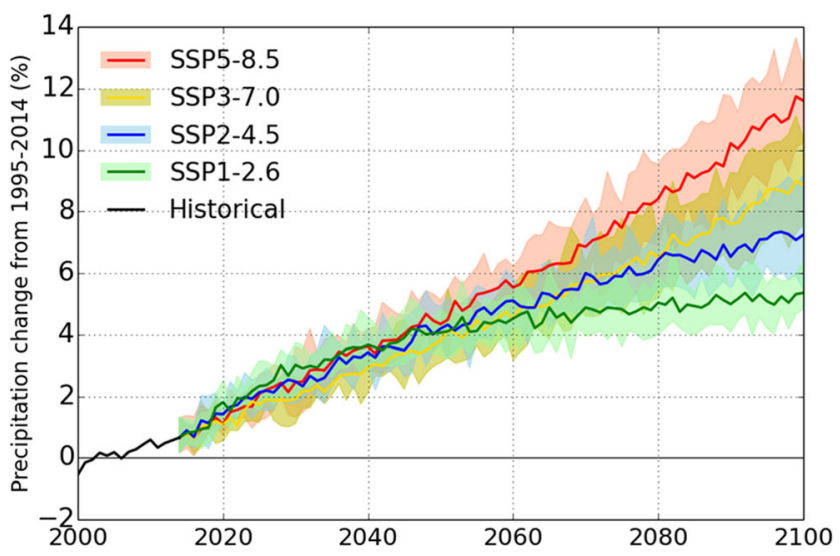

\subsection{Climate Extremes Index}

We use the Expert Team on Climate Change Detection and Indices (ETCCDI) to define a set of climate indices (Klein Tank et al. 2009, Sillmann et al. 2013). To investigate the future projections of climate extremes, warm days (above the 90th percentile of daily maximum temperature; TX90p) and cold nights (below the 10th percentile of daily minimum temperature; TN10p), and very wet days (above the 95th percentile of daily precipitation amount; R95p) of ETCCDI are used.

Figure 8 shows the spatial distributions of extreme indices (TX90p, TN10p, and R95p) for the LT period. Relative to PD level, TX90p increases three times especially in Central Africa, western India, southern China, Southeast Asia,

Fig. 5 Time series of global mean precipitation changes (\%) for the historical simulation (black) from 1995 to 2014, and future simulations for four SSP-RCPs (SSP5-8.5 (red), SSP3-7.0 (yellow), SSP2-4.5 (blue), and SSP1-2.6 (green)) from 2015 to 2100 , respectively. The shaded area indicates the ensemble spread of six members (both K-ACE and UKESM1)

Central America, and northern South America regions. Also, TN10p is decreased about 93\% compared with the PD level especially in northern and southern Africa, Europe, Russia, Australia, and high elevation regions including major 

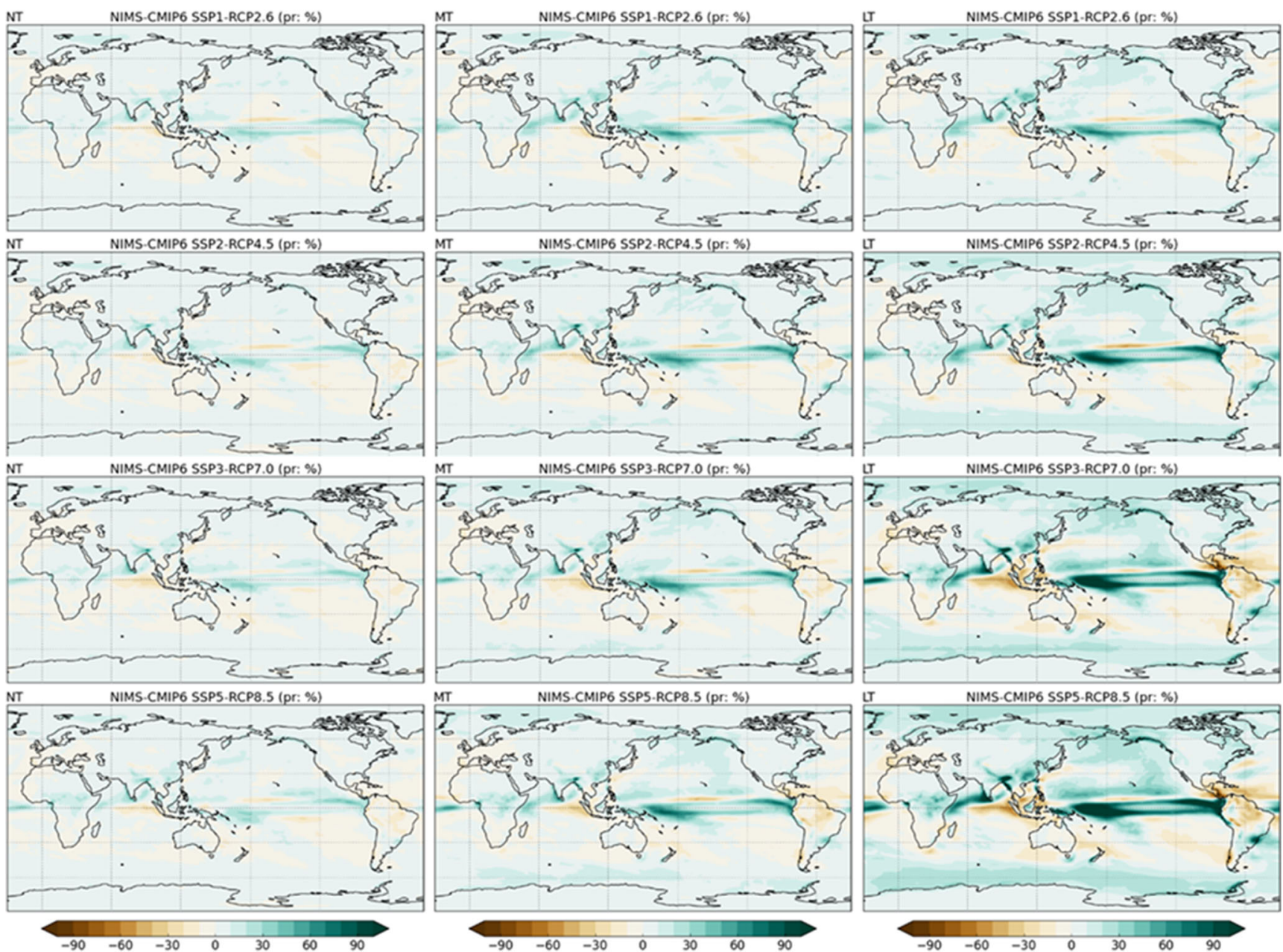

Fig. 6 Global distribution of the 20 year precipitation change (\%) in twenty-first century of four SSP-RCP future scenarios (SSP1-2.6 (first (fourth row)) with three future periods (Near-Term (NT; left column), Mid-Term (MT; mid column), and Long-Term (LT; right column)) compared to PD period (1995-2014)
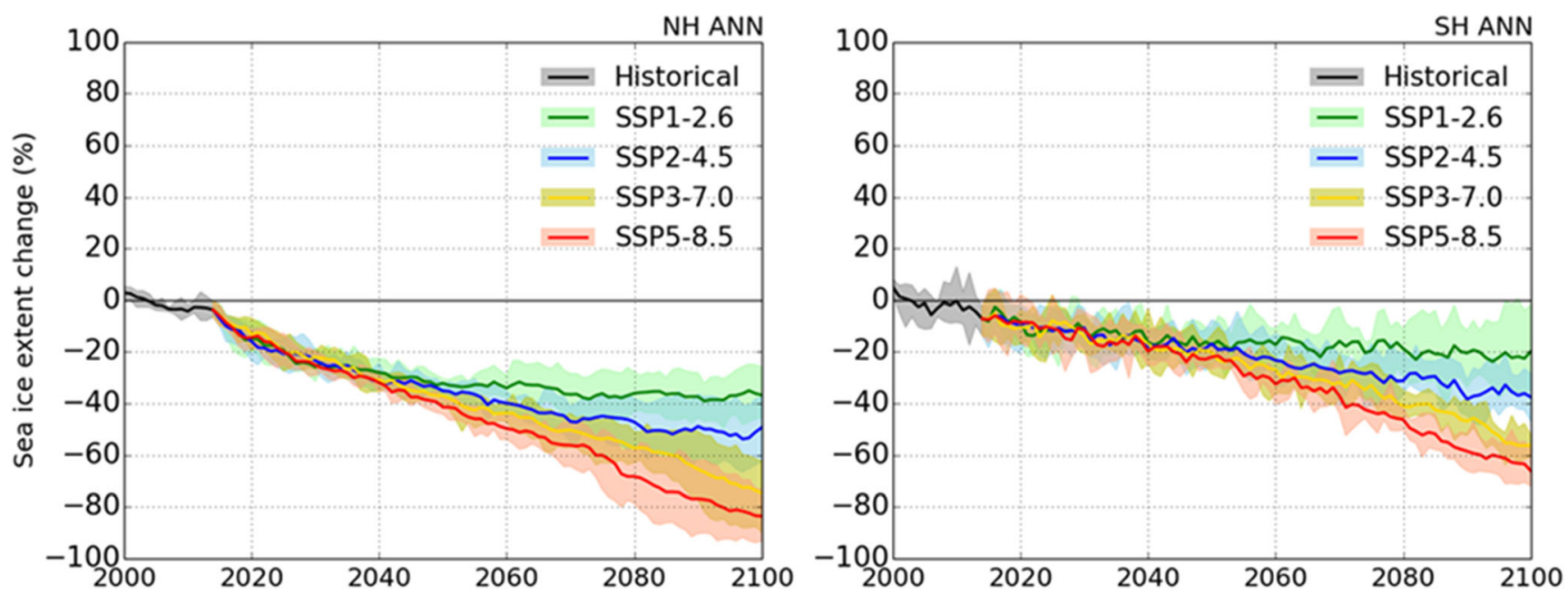

Fig. 7 Time series of sea ice extent change $\left(10^{6} \mathrm{~km}^{2}\right)$ in (a) the Arctic and (b) the Antarctic for historical simulation (black) and future simulations for four SSP-RCPs (SSP5-8.5 (red), SSP3-7.0 (yellow), SSP2-4.5

(blue), and SSP1-2.6 (green)) relative to PD level (1995-2014), respectively. Shaded area indicates ensemble spread of six members (both KACE and UKESM1) 

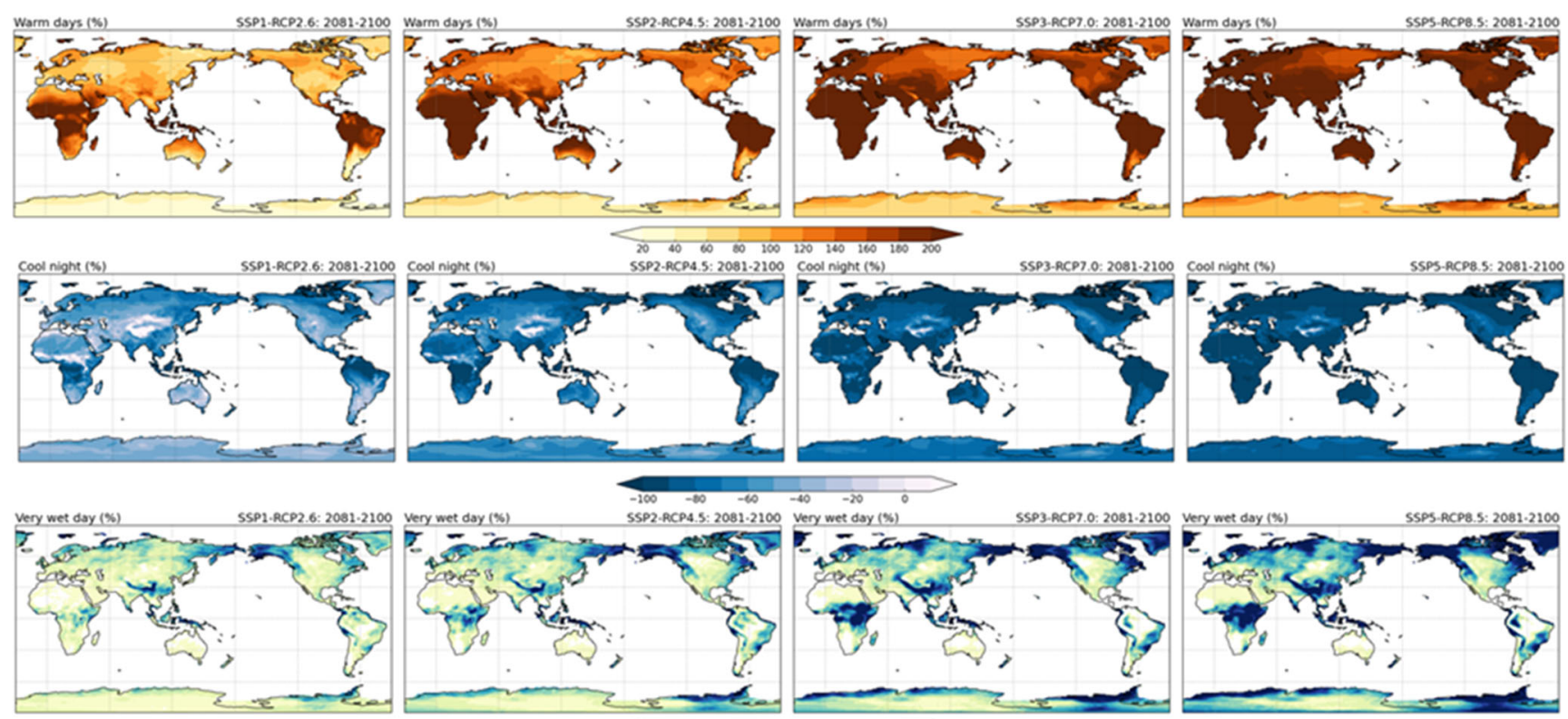

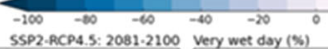

SSP3-RCP7.0: 2081-2100 very wet day (\%)

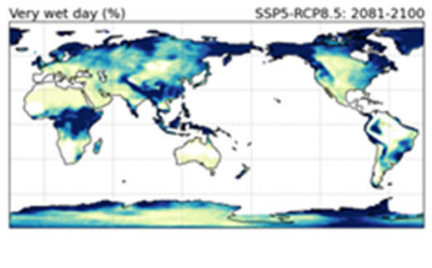

Fig. 8 Spatial distributions of warm days (TX90p; top), cold nights (TN10p; middle), and very wet days (R95p; bottom) in LT (2081 2100) relative to the PD (1995 2014). Unit is \%

mountain ranges (e.g., the Rockies, the Andes, and the Alps) and the Tibetan plateau. Overall, change in TX90p and TN10p mainly occurs in low to mid latitude regions with high elevation, respectively. These results are consistent with the CMIP5 projections (IPCC 2014, 2019). Furthermore, the R95p projections in LT period from 15\% in SSP1-2.6 to $54 \%$ in SSP5-8.5, and the spatial pattern of R95p changes mainly occur in low-latitude and high-latitude regions (e.g., Central Africa, Southeast Asia, northern South America, Alaska, and Scandinavia). This increasing trend in climate extreme indices is similar with Baek et al. (2013), however the rate of change in the LT period is higher. This demonstrates that the response to future extremes due to SSP-RCP is stronger than in RCP scenarios.

\section{Summary and Discussion}

Understanding climate change induced from anthropogenic forcing is important to determine the future directions of socioeconomic development. The SSP-RCP scenarios have been developed for the new phase of CMIP that is currently underway (O'Neill et al., 2016). The NIMS-KMA produces climate projections with new scenarios and this study summarizes the main findings of that effort.

(1) NIMS-KMA produces new CMIP6 scenario using the ensemble mean of two models (K-ACE and UKESM1) and an evaluation of CMIP6 historical simulation is performed in this study compared to CMIP5 simulations.
The results of performance index for 20 climate variables reveal that the NIMS-KMA-CMIP6 simulation shows better performance in PD period compared to CMIP5 simulations. In addition to the mean state, model simulations capture the observed characteristics of extratropical modes of variability (i.e., NAM, NAO, PNA, NPO, SAM, PDO, and NPGO). Overall, these results demonstrate the high reliability of future projections for the twenty-first century.

(2) Projected global warming and increasing precipitation are proportional to scenarios. Future changes in the LT period are larger than in the NT period. These results are consistent with CMIP5, but the increments are larger in this study based on SSP-RCPs.

In the LT period, projected temperature and precipitation depend on the scenarios associated with GHG forcing. On average, the projected range of temperature changes in the LT period relative to the PD period is expected to be $1.92 \pm 0.22{ }^{\circ} \mathrm{C}, 3.02 \pm 0.47{ }^{\circ} \mathrm{C}, 4.28 \pm$ $0.62{ }^{\circ} \mathrm{C}$, and $5.20 \pm 0.71{ }^{\circ} \mathrm{C}$ for SSP $1-2.6$, SSP2-4.5, SSP3-7.0, and SSP5.8.5, respectively. Precipitation increases from $5.1 \%$ to $10.1 \%$ and sea ice extent reduces from $19 \%$ to $62 \%$ in the Arctic and from $18 \%$ to $54 \%$ in the Antarctic. Future changes in temperature and precipitation increments are larger than results reported by Baek et al. (2013), owing to the large $\mathrm{CO}_{2}$ concentrations in the SSP-RCP scenario and higher climate sensitivity of CMIP6 models.

(3) To investigate the future projection of climate extremes, TX90p, TN10p, and R95p indices are used in this study. Spatial patterns of these indices are similar to CMIP5, 
but the magnitudes are significantly larger than CMIP5.

The spatial pattern of the indices (Fig. 8) is in good agreement with the CMIP5 models. In LT period, TX90p increases three times and TN10p decreases about $93 \%$ relative to PD period. The R95p increases from $15 \%$ in SSP1-2.6 to 54\% in SSP5-8.5. This increasing trend of climate extreme indices is similar to CMIP5, but the magnitudes are larger than CMIP5.

Acknowledgments This work was funded by the Korea Meteorological Administration Research and Development Program "Development and Assessment of IPCC AR6 Climate Change Scenarios" under Grant (KMA2018-00321). UKESM1 is in collaboration with U.K. Met Office. Work of Jiwoo Lee was performed under the auspices of the U.S. Department of Energy (BER, RGMA Program) by Lawrence Livermore National Laboratory under Contract DE-AC52-07NA27344.

Open Access This article is licensed under a Creative Commons Attribution 4.0 International License, which permits use, sharing, adaptation, distribution and reproduction in any medium or format, as long as you give appropriate credit to the original author(s) and the source, provide a link to the Creative Commons licence, and indicate if changes were made. The images or other third party material in this article are included in the article's Creative Commons licence, unless indicated otherwise in a credit line to the material. If material is not included in the article's Creative Commons licence and your intended use is not permitted by statutory regulation or exceeds the permitted use, you will need to obtain permission directly from the copyright holder. To view a copy of this licence, visit http://creativecommons.org/licenses/by/4.0/.

\section{References}

Archibald, A.T., O'Connor, F.M., Abraham, N.L., Archer-Nicholls, S., Chipperfield, M.P., Dalvi, M., Folberth, G.A., Dennison, F., Dhomse, S.S., Griffiths, P.T., Hardacre, C., Hewitt, A.J., Hill, R.S., Johnson, C.E., Keeble, J., Kohler, M.O., Morgenstern, O., Mulcahy, J.P., Ordones, C., Pope, R.J., Rumbold, S.T., Russo, M.R., Savage, N.H., Sellar, A.A., Stinger, M., Turnock, S.T., Wild, O., Zeng, G.: Description and evaluation of the UKCA stratosphere-troposphere chemistry scheme (StratTrop vn1.0) implemented in UKESM1. Geosci. Model Dev. 13, 1223-1266 (2019)

Baek, H.-J., Lee, J., Lee, H.-S., Hyun, Y.-K., Cho, C., Kwon, W.-T., Marzin, C., Gan, S.-Y., Kim, M.-J., Choi, D.-H., Lee, J., Lee, J., Boo, K.-O., Kang, H.-S., Byun, Y.-H.: Climate change in the 21st century simulated by HadGEM2-AO under representative concentration pathways. Asia-Pac. J. Atmos. Sci. 49, 603-618 (2013)

Best, M.J., Pryor, M., Clark, D.B., Roone, G.G., Essery, R.L.H., Menard, C.B., Edwards, J.M., Hendry, M.A., Porson, A., Gedney, N., Mercado, L.M., Sitch, S., Blyth, E., Boucher, O., Cox, P.M., Grimmond, C.S.B., Harding, R.J.: The joint UK land environment simulator (JULES), model description - part 1: energy and water fluxes. Geosci. Model Dev. 4, 677-699 (2011)

Bond, T.C., Streets, D.G., Yarber, K.F., Nelson, S.M., Woo, J.-H., Klimont, Z.: A technology-based global inventory of black and organic carbon emissions from combustion. J. Geophys. Res. 109, D14203 (2004)

Collins, W.J., Bellouin, N., Doutriaux-Boucher, M., Gedney, N., Halloran, P., Hinton, T., Hughes, J., Jones, C.D., Joshi, M., Liddicoat, S., Martin, G., O'Connor, F.O., Rae, J., Senior, C., Sitch, S., Totterdell, I., Wiltshire, A., Woodward, S., S.:
Development and evaluation of an earth system model-HadGEM2. Geosci. Model Dev. 4, 1051-1075 (2011)

Compo, G.P., Whitaker, J.S., Sardeshmukh, P.D.: Feasibility of a 100year reanalysis using only surface pressure data. Bull. Am. Meteorol. Soc. 87, 175-190 (2006)

Compo, G.P., Whitaker, J.S., Sardeshmukh, P.D., Matsui, N., Allan, R.J., Yin, X., Gleason, B.E., Vose, R.S., Rutledge, G., Bessemoulin, P., BroNnimann, S., Brunet, M., Crouthamel, R.I., Grant, A.N., Groisman, P.Y., Jones, P.D., Kruk, M.C., Kruger, A.C., Marshall, G.J., Maugeri, M., Mok, H.Y., Nordli, O., Ross, T.F., Trigo, R.M., Wang, X.L., Woodruff, S.D., Worley, S.J.: The twentieth century reanalysis project. Q. J. R. Meteorol. Soc. 137, 1-28 (2011)

Cvijanovic, I., Ken, C.: Atmospheric impacts of sea ice decline in $\mathrm{CO}_{2}$ induced global warming. Clim. Dyn. 44, 1173-1186 (2015)

Craig, A., Valcke, S., Coquart, L.: Development and performance of a new version of the OASIS coupler, OASIS3-MCT 3.0. Geosci Model Dev. 10, 3297-3308 (2017)

Durack, P.J., Taylor, K.E., Eyring, V., Ames, S.K., Hoang, T., Nadeau, D., Doutriaux, C., Stockhause, M., Gleckeler, P.J.: Toward standardized data sets for climate model experimentation, Eos, 99, doi: https://doi.org/10.1029/2018EO101751, (2018)

Eyring, V., Bony, S., Meehl, G.A., Senior, C.A., Stevens, B., Stouffer, R.J., Taylor, K.E.: Overview of the coupled model Intercomparison project phase 6 (CMIP6) experimental design and organization. Geosci. Model Dev. 9, 1937-1958 (2016)

Gidden, M.J., Riahi, K., Smith, S.J., Fujimori, S., Luderer, G., Kriegler, E., van Vuuren, D.P., van den Berg, M., Feng, L., Klein, D., Calvin, K., Doelman, J.C., Frank, S., Fricko, O., Harmsen, M., Hasegawa, T., Havlik, P., Hilaire, J., Hoesly, R., Horing, J., Popp, A., Stehfest, E., Takahashi, K.: Global emissions pathways under different socioeconomic scenarios for use in CMIP6; a dataset of harmonized emissions trajectories through the end of the century. Geosci. Model Dev. 12, 1443-1475 (2019)

Gleckler, P., Doutriaux, C., Durack, P., Taylor, K., Zhang, Y., Williams, D., Mason, E., Servonnat, J.: A more powerful reality test for climate models. Eos. 97, 1-8 (2016)

Gregory, J.M., Stott, P.A., Cresswell, D.J., Rayner, N.A., Gordon, C., Sexton, D.M.H.: Recent and future changes in Arctic Sea ice simulated by the HadCM3 AOGCM. Geophs. Res. Lett. 29, 2175 (2002)

Griffies, S. M., Harrison, M.J., Pacanowski, R.C., Rosati, A.: A technical guide to MOM, GFDL Ocean group technical report no. 5, NOAA/ Geophysical Fluid Dynamics laboratory, (2007)

Hunke, E.C., Lipscomb, W.H., Turner, A.K., Jeffery, N., and Elliott, S.: CICE: the Los Alamos Sea Ice Model Documentation and Software user's Manual, Techical Report, LA-CC-06-012, Los Alamos National Laboratory, (2015)

IPCC: Climate change 2013: the physical science basis. Contribution of working group I to the fifth assessment report of IPCC the intergovernmental panel on climate change (eds. Stocker, T. F., D. Qin, G.K. Plattner, M. M. B. Tignor, S. K. Allen, J. Boschung, A. Nauels, Y. Xia, V. Bex, P. M. Midgley), Cambridge University press, Cambridge, United Kingdom and New York, NY, USA, (2014)

IPCC: Summary for Policymakers. In: IPCC Special Report on the Ocean and Cryosphere in a Changing Climate (eds. Portner, H.-O., D. C. Robert, V. Masson-Delmotte, P. Zhai, M. Tignor, E. Poloczanska, K. Mintenbeck, A. Alegria, M. Nicolai, A. Okem, J. Petzold, B. Rama, and N. M. Weyer), In press, (2019)

Klein Tank, A.M.G., Zwiers, F.W., Zhang, X.: Guidelines on analysis of extremes in a changing climate in support of informed decisions for adaptation, Climate data and moniroting WCDMP-No. 72, WMOTD No. 1500, pp. 56pp, (2009)

Lee, J., Kim, J., Sun, M.-A., Kim, B.-H., Moon, H., Sung, H.M., Kim, J., Lim, Y.-J., Byun, Y.-H.: Evaluation of the Korea Meteorological Administration advanced community earth-system model (K-ACE). Asia-Pac. J. Atmos. Sci. 56, 381-395 (2019a). https://doi.org/10. 1007/s13143-019-00144-7 
Lee, J., Sperber, K., Gleckler, P., Bonfils, C., Taylor, K.: Quantifying the agreement between observed and simulated Extratropical modes of interannual variability. Clim. Dyn. 52, 4057-4089 (2019b)

Min, S.-K., Stephanie, L., Andreas, H., Ulrich, C., Kwon, W.-T., Oh, J.H., Ulrich, S.: East Asian climate change in the $21^{\text {st }}$ century as simulated by the coupled climate model ECHO-G under IPCC SRES scenarios. J. meteor. Soc. Japan. 84, 1-26 (2006)

Moss, R.H., Edmonds, J.A., Hibbard, K.A., Manning, M.R., Rose, S.K., van Vuuren, D.P., Carter, T.R., Emori, S., Kainuma, M., Kram, T., Meehl, G.A., Mitchell, J.F., Nakicenovic, N., Riahi, K., Smith, S.J., Thomson, A.M., Weyant, J.P., Wilbanks, T.J.: The next generation of scenarios for climate change research an assessment. Nature. 63, $747-756$ (2010)

Meinshausen, M., Vogel, E., Nauels, A., Lorbacher, K., Meinshausen, N., Etheridge, D.M., Frased, P.J., Montzka, S.A., Rayner, P.J., Trudinger, C.M., Krummel, P.B., Beyerle, U., Canadell, J.G., Daniel, J.S., Enting, I.G., Law, R.M., Lunder, C.R., O’Doherty, S., Prinn, R.G., Reimann, S., Rubino, M., Velders, G.J.M., Vollmer, M.K., Wang, R.H.J., Weiss, R.: Historical greenhouse gas concentrations for climate modeling (CMIP6). Geosci. Model Dev. 10, 2057-2116 (2017)

Mulcahy, J.P., Jones, C., Sellar, A.A., Johnson, B., Boutle, I.A., Jones, A., Andrews, T., Rumbold, S.T., Mollard, J., Bellouin, N., Johnson, C.E., Williams, K.D., Grosvenor, D.P., McCoy, D.T.: Improved aerosol processes and effective radiative forcing in HadGEM3 and UKESM1. J. Adv. Model. Earth Syst. 10, 2786-2805 (2018)

O’Neill, B.C., Tebaldi, C., van Vuuren, D.P., Eyring, V., Friedlingstein, P., Hurtt, G., Knutti, R., Kriegler, E., Lamarque, J.-F., Lowe, J., Meehl, G.A., Moss, R., Riahi, K., Sanderson, B.M.: The scenario model Intercomparison project (ScenarioMIP) for CMIP6. Geosci. Model Dev. 9, 3461-3482 (2016)

Rayner, N.A., Parker, D.E., Horton, E.B., Folland, C.K., Alexander, L.V., Rowell, D.P., Kent, E.C., Kaplan, A.: Global analyses of sea surface temperature, sea ice, and night marine air temperature since the late nineteenth century. J. Geophys. Res. 108, 4407 (2003). https://doi.org/10.1029/2002JD002670

Reichler, T., Kim, J.: How well do coupled models simulate today's climate? Bull. Amer. Meteor. Soc. 89, 303-311 (2008)

Ridley, J.K., Blockley, E.W., Keen, A.B., Rae, J.G.L., West, A.E., Schroeder, D.: The sea ice model component of HadGEM3GC3.1. Geosci. Model Dev. 11, 713-723 (2018)

Sellar, A.A., Jones, C.G., Mulcahy, J.P., Tang, Y., Yool, A., Wiltshire, A., O'Connor, F.M., Stringer, M., Hill, R., Palmieri, J., Woodward, S., Mora, L., Kuhlbrodt, T., Rumbold, S.T., Kelley, D.I., Ellis, R.,
Johnson, C.E., Walton, J., Abraham, N.L., Andrews, M.B., Andrews, T., Archibald, A.T., Berthou, S., Burke, E., Blockley, E., Carslaw, K., Dalvi, M., Edwards, J., Folberth, G.A., Gedney, N., Griffiths, P.T., Harper, A.B., Hendry, M.A., Hewitt, A.J., Johnson, B., Jones, A., Jones, C.D., Keeble, J., Liddicoat, S., Morgenstern, O., Parker, R.J., Predoi, V., Robertson, E., Siahaan, A., Smith, R.S., Swaminathan, R., Woodhouse, M.T., Zeng, G., Zerroukat, M.: UKESM1: description and evaluation of the UK earth system model. J. Adv. Model. Earth Syst. 11, 4513-4558 (2019)

Sillmann, J., Kharin, V.V., Zhang, X., Zwiers, F.W., Bronaugh, D.: Climate extremes indicies in the CMIP5 multimodel ensemble: Part1. Model evaluation in the present climate. J. Geophys. Res. Atmos. 118, 1716-1733 (2013)

Sun, M.-A., Sung, H.M., Kim, J., Lim, Y.-J., Marzin, C., Byun, Y.-H.: Diagnosing climate sensitivity and feedback to idealized $\mathrm{CO} 2$ forcing: a comparison between the K-ACE and CMIP models, Asia-Pac. J. Atmos. Sci., (under review), (2020)

Valcke, S., Craig, T., Coquart, L.: OASIS3-MCT user guide, OASIS3MTC 3.0, technical report, $T R / C M G C / 15 / 38$, CERFACS No1875, Toulouse, France, (2015)

Velders, G.J.M., Fahey, D.W., Daniel, J.S., McFarland, M., Andersen, S.O.: The large contribution of projected HFC emissions to future climate forcing. P. Natl. Acad. Sci. USA. 106, 10949-10954 (2009)

Walters, D., A. J. Baran, I. Boutle, M. Brooks, P. Earnshaw, J. Edwards, K. Furtado, P. Hill, A. Lock, J. Manners, C. Morcrette, J. Mulcahy, C. Sanchez, C. Smith, R. Stratton, W. Tennant, L. Tomassini, K. Van Weverberg, S. Vosper, M. Willett, J. Browse, A. Bushell, K. Carslaw, M. Dalvi, R. Essery, N. Gedney, S. Hardiman, B. Johnson, C. Johnson, A. Jones, C. Jones, G. Mann, S. Milton, H. Rumbold, A. A. Sellar, M. Ujiie, M. Whitall, K. Williams, M. Zerroukat, 2019: The Met Office Unified Model Global Atmosphere 7.0/7.1 and JULES Global Land 7.0 configurations. Geosci. Model Dev. 12, 1909-1963

WMO: Scientific Assessment of Ozone Depletion, 416 pp. World Meteorological Organization, Geneva (2014)

Zelinka, M.D., Myers, T.A., McCoy, D.T., Po-Chedley, S., Caldwell, P.M., Ceppi, P., Klein, S.A., Taylor, K.E.: Causes of higher climate sensitivity in CMIP6 models. Geophs. Res. Lett. 47, e2019GL085782 (2020)

Publisher's Note Springer Nature remains neutral with regard to jurisdictional claims in published maps and institutional affiliations. 